\title{
Selected Topics in Management and Modeling of Complex Systems: Editorial Introduction to Issue 16 of CSIMQ
}

\author{
Peter Forbrig* \\ Institute of Computer Science, Chair of Software Engineering, University of Rostock, \\ Albert-Einstein-Str. 22, D-18055 Rostock, Germany \\ peter.forbrig@uni-rostock.de
}

The topics of the 16th issue of CSIMQ range from psychological aspects of sustainable behavior change within organizations while new technologies are introduced into a company to detailed algorithms for Big Data analysiss.

The first paper by Danny Oldenhave, Jos Sauren, Theo van der Weide and Stijn Hoppenbrouwers discusses the already mentioned psychological aspects of introducing new technologies into companies. The authors are all from the Netherlands. Two of them work at universities and two of them are from the application domain enterprises. They argue that the introduction of new technologies in organizations requires not only a change in ways of working, but also a change of thinking of the employees. They shortly discuss the design method that is called Persuasive and Motivational Design (PMD). Afterwards, an evaluation of PMD for its usefulness and effectiveness is provided. The title of the paper is "Evaluating the Persuasive and Motivational Design Method Supporting Design for Sustainable Behavior Change."

The second article is by Dierk Jugel. He provides an approach for modeling enterpise architecture visualisations. Enterprise architecture management aims at providing an integrated view on processes, organizational units, resources, and technologies. Different stakeholders are interested in specific aspects. Since they have different interests, it is important to align visualizations to their demands. These different visualizations are called viewpoints. The author provides an approach for developing cockpits that are composed of viewpoints. It is applied to specify and develop an architecture cockpit for a company from the financial sector. The article is entitled "Modeling Interactive Enterprise Architecture Visualizations: An Extended Architecture Description."

The third paper by Ilia Bider, Paul Johannesson, and Erik Perjons discusses the concepts of shared spaces that originally stems from computer supported cooperative work as a basis for building business process support systems. In the paper, a generic model is suggested that supports the comparison, analysis, and design of business process support systems. Additionally,

\footnotetext{
* Corresponding author

(C) 2018 Peter Forbrig. This is an open access article licensed under the Creative Commons Attribution License (http://creativecommons.org/licenses/by/4.0).

Reference: P. Forbrig, "Selected Topics in Management and Modeling of Complex Systems: Editorial Introduction to Issue 16 of CSIMQ," Complex Systems Informatics and Modeling Quarterly, CSIMQ, no. 16, pp. I-II, 2018. Available: https://doi.org/10.7250/csimq.2018-16.00

Additional information. Author's ORCID iD: P. Forbrig - orcid.org/0000-0003-3427-0909. PII S225599221800091X. Received: 27 October 2018. Available online: 31 October 2018.
} 
two existing business process support systems are compared according to the findings. The title of the paper is "Structured Shared Spaces as a Basis for Building Business Process Support Systems: A Generic Model and Analysis of Examples."

The special issue closes with an article by Alieh Saeedi, Markus Nentwig, Eric Peukert, and Erhard Rahm from the University of Leipzig and the Competence Center for Scalable Data Science Services and Solutions (ScaDS) Dresden/Leipzig. They discuss specific algorithms that allow entity clustering for Big Data analysis. The goal of these algorithms is the identification of different notations of references that refer to the same real-world object. This entity resolution is also called dedublication. They call their own approach FAMER that stands for FAst Multisource Entity Resolution system. It is used for multi-source entity resolution that supports clustering matching entities and exploits both blocking and distributed processing. The article is an extended version of a paper from the 21st European Conference on Advances in Databases and Information Systems (ADBIS 2017) and is entitled: "Scalable Matching and Clustering of Entities with FAMER."

The published articles support management and modeling of complex systems in very different ways on very different levels of abstraction. The discussed ideas might be interesting for the readers and cross-pollinate each other. 